\title{
EFFECT OF INTERTROCHANTERIC OSTEOTOMY ON THE PROXIMAL FEMUR OF RABBITS: ASSESSMENT WITH POWER DOPPLER SONOGRAPHY AND SCINTIGRAPHY
}

\author{
Andrea S. Doria ${ }^{2}$, Fabiano G. Cunha ${ }^{1}$, Marcelo Modena ${ }^{1}$, Consuelo Junqueira \\ Rodrigues $^{3}$, Alexandre Teles Garce ${ }^{4}$, Rui de Godoy Junior ${ }^{1}$, Raul Bolliger Neto ${ }^{1}$, \\ Ivani Bortoleti Melo ${ }^{4}$, Carlos Buchpiguel ${ }^{4}$, Laszlo J. Molnar ${ }^{4}$, Roberto Guarniero ${ }^{1}$
}

Doria AS, Cunha FG, Modena M, Rodrigues CJ, Garcez AT, Junior RG, Bolliger Neto R, Melo IB, Buchpiguel C, Molnar LJ, Guarniero R. Effect of intertrochanteric osteotomy on the proximal femur of rabbits: assessment with power doppler sonography and scintigraphy. Clinics. 2007;62(6):741-8.

OBJECTIVE: In bone injury, repair results in local increased vascularity and bone marrow remodeling. Characterizing the vascular and metabolic imaging patterns of the proximal femur following an intertrochanteric osteotomy may help clinicians decide proper management of the patient. Our objective was to measure Doppler sonography and scintigraphy interval changes in the proximal femur following intertrochanteric osteotomy and compare imaging and histomorphometric measurements in the late post-operative stage ( 6 weeks after surgery) in a rabbit model of bone injury.

MATERIALS AND METHODS: Both hips of 12 adult rabbits were imaged with power Doppler sonography and scintigraphy prior to and after ( 7 days and 6 weeks) unilateral osteotomy. Accuracy of the imaging methods was evaluated using hip operative status and histomorphometric results (vascular fractional area and number of vessels per area unit) as reference standard measures. RESULTS: A significant difference in the mean number of pixels was noted between operated and non-operated femura in late post-operative power Doppler examinations $(\mathrm{P}=0.049)$. Although without reaching statistical significance, the AUC of Doppler measurements (AUC $=0.99$ ) was numerically greater than the $\mathrm{AUC}$ of scintigraphy measurements $(\mathrm{AUC}=0.857 \pm 0.099)(\mathrm{P}=0.15)$ in differentiating proximal femura with regard to their fractional vascular areas in the late post-operative stage. In contrast, scintigraphy tended to perform better $(\mathrm{AUC}=0.984 \pm 0.022$ ) than Doppler ultrasound ( $\mathrm{AUC}=0.746 \pm 0.131$ ) to demonstrate the vascularity intensity per area unit $(\mathrm{P}=0.07)$ in the late stage.

CONCLUSION: Our results warrant further investigation to determine the value of different imaging modalities for assessment of pathologic changes following hip surgery. Power Doppler sonography demonstrated larger AUCs (representing higher accuracy) for the discrimination of vascular fractional areas and scintigraphy, for discrimination of the number of vessels per area unit.

KEYWORDS: Intertrochanteric Osteotomy, Power Doppler Ultrasound, Scintigraphy, Rabbits, Femur.

1. Department of Orthopedic Surgery of Hospital das Clinicas da Universidade de São Paulo-SP, Brazil

2. Department of Diagnostic Imaging, The Hospital for Sick Children, University of Toronto, Canada

3. Department of Pathology of Hospital das Clinicas da Universidade de São Paulo-SP, Brazil

4. Department of Nuclear Medicine of Radiology Institute of Hospital das Clinicas da Universidade de São Paulo-SP, Brazil

5. Department of Diagnostic Imaging of Heart Institute of Hospital das Clinicas da Universidade de São Paulo-SP, Brazil

Email: andrea.doria@sickkids.ca

Received for publication on June $1^{\text {st }}, 2007$

Accepted for publication on August 14, 2007

\section{INTRODUCTION}

Intertrochanteric varus osteotomies have been widely used in humans to treat severe slipped capital femoral epiphysis $^{1}$, Legg-Calve-Perthes' disease ${ }^{2}$, and congenital anomalies such as congenital coxa vara ${ }^{3}$ and spastic encephalopathy ${ }^{4}$. Surgical interventions, such as osteotomies, stimulate growth in long bones ${ }^{5-7}$. In these circumstances bone growth occurs in response to disturbances of the vascular supply to the proximal epiphysis and metaphysis. Car- 
tilage proliferation and repair result in increased vascularity and remodeling in the adjacent bone marrow ${ }^{8}$. Whereas the proliferation of cartilage cells is mainly dependent on the blood supply to the epiphysis, primary calcification and endochondral ossification are dependent on the blood supply to the metaphysis. Thus, stimulation of growth requires increased vascular supply to the epiphysis ${ }^{5}$.

Non-invasive imaging modalities, such as Doppler sonography and scintigraphy, may be able to recognize the vascular and metabolic imaging patterns that are seen in the proximal femoral epiphysis following an intertrochanteric femoral osteotomy, thus helping clinicians decide on proper management. In contrast to sonography that uses a small field-of-view (FOV) for visualization of increased vascularity in the epiphysis, scintigraphy provides a larger FOV for the assessment of proximal femur bone metabolism. Scintigraphy, however, bears radiation which somewhat limits its use in humans. Doppler sonography does not bear radiation ${ }^{9-12}$, but is operator-dependent, requiring trained personnel to systematically perform the examinations. Previous Doppler studies evaluating early reversible ischemia of the capital femoral epiphysis in piglets showed that contrast-enhanced power Doppler sonography could identify the vascular supply to the femoral head and detect reversible ischemia induced by hip hyperabduction ${ }^{13}$. Previous scintigraphic studies ${ }^{14}$ showed increased metabolism in the proximal femur as a result of increased local perfusion after intertrochanteric osteotomy. Post-operative changes, however, have been poorly investigated with these two imaging modalities. The effect of osteotomies on the proximal femoral vascularity in rabbit models have been well demonstrated histologically in previous studies ${ }^{5-7}$, confirming the effectiveness of this surgical procedure in producing healing of the proximal femur by means of neovascularization.

In this study we evaluated the vascularity of the proximal femoral epiphysis of rabbits prior to and following an adjacent intertrochanteric osteotomy using power Doppler sonography and scintigraphy. The goals of our study were to measure Doppler sonography and scintigraphy interval changes in the proximal femur following an intertrochanteric osteotomy, and to compare imaging and histomorphometric measurements in the late post-operative stage ( 6 weeks after the surgical procedure) in a rabbit model of bone injury.

\section{SUBJECTS AND METHODS}

Our study protocol received approval from the Animal Care Committee of the institution where the study was conducted.

\section{Animal Protocol}

Twelve adult New Zealand white rabbits (mean weight, at the beginning of the experiment $3.750 \mathrm{~g}$ ) were evaluated prior to and after an intertrochanteric osteotomy. Immediately prior to surgery, both rabbits' hips were evaluated by power Doppler sonography and scintigraphy. Prior to each imaging procedure the animals were anesthesized with an intramuscular injection of 11 to $15 \mathrm{mg} / \mathrm{kg}$ of ketamine hydrochloride (Ketalar; Parke-Davis, Morris Plains, NJ) and $1.1 \mathrm{mg} / \mathrm{kg}$ of xylazine hydrochloride (Rompun; Miles, Shawnee, KS). One of the rabbits' hips was randomly selected to undergo the surgical procedure. On the seventh day (recent post-operative stage) and sixth week (late post-operative stage) after the surgical procedure, both hips were again imaged with power Doppler sonography and scintigraphy.

\section{Imaging Acquisition}

Power Doppler Sonography. The rabbits' hips were scanned in a supine position with an HDI 5000 (Advanced Technology Laboratories Inc., Philips, Bothell, WA) ultrasound scanner using a $10-\mathrm{MHz}$ linear-array transducer. Sagittal and transverse anterior planes were scanned by a single sonologist, using medium filter, pulse repetition frequency of $700 \mathrm{~Hz}, 79 \%$ of color gain, and a depth of 2.9 $\mathrm{cm}$. The transducer was placed on the hip joint region corresponding to the proximal femoral epiphysis and was held in place manually during the performance of the examination. The sonologist could not be blinded with regards to the surgical status (operated vs non-operated) of the hip joints.

Scintigraphy. The animals were injected with technetium-99m-labelled methylene diphosphonate (13 MBq $/ \mathrm{kg}$ ). Three hours later, planar projection scintigrams of the hips were acquired using an Orbiter Stand gamma camera (Siemens Gammasonics Inc., U.S.A.), 128 x 128 matrix, fitted with a pinhole collimator that had an aperture diameter of $4 \mathrm{~mm}$. One hundred and fifty thousand counts were obtained per image. Magnified frontal views of the hips were acquired with pinhole collimation at the static phase.

Intertrochanteric Osteotomy Technique. The anesthesized animals were placed in the lateral decubitus position, and a total osteotomy was performed in the intertrochanteric region, followed by internal fixation as described elsewhere ${ }^{5}$. A single dose of intramuscular penicillin $\mathrm{G}$ benzatin, 30,000 $\mathrm{U} / \mathrm{kg}$ was administered intraoperatively to prevent infection.

Abdominal Aorta Arteriography. Immediately prior to euthanasia of the animals, 5,000 $\mathrm{U}$ of heparin was given 
intraarterially. The abdominal aorta of the anesthesized animals was then catheterized and direct arteriography of both common iliac arteries, superficial and profunda femoral arteries, and their branches was performed with a solution of barium sulfate (Micropaque, Nicholas Laboratories, Slough, England) ${ }^{15}$. The pelvis and lower limbs of each animal were then radiographed in the anterior-posterior view with the hip in $90^{\circ}$ flexion and $45^{\circ}$ abduction. This procedure was done to confirm increased vascularity in the operated region at 6 weeks from the surgical procedure.

\section{Imaging Analysis}

Power Doppler Sonography. The radiologist interpreting the power Doppler examination was not involved with the interpretation of the radionuclide study. The images were recorded on a digital image processing unit of the ultrasound scanner and were printed out upon the end of each examination. The images were then scanned from the hard copies (Scanner Color Page HR5-PRO Kye Systems Corp, Taiwan) and analysed with a PC computer using Photoshop 5.0; Adobe Systems, Mountain View, Calif. The reproduced images represented similar anatomic regions of the femoral head. In these images, regions-of-interest (ROIs) containing color pixel information were drawn over the area of the femoral head included within the color Doppler box (Fig. 1A-F) by a single operator blinded to all clinical and surgical information, date of examination and results of other imaging tests. The mean intensity of pixels for each ROI of the hip at each time point was calculated with the computer program's histogram function. After determining the mean color pixel intensity within selected ROIs of the two hips, we matched the results with corresponding surgical and temporal information and compared the pixel intensity between the two hips using the following formula: pixel intensity ratio $=[$ (mean pixel intensity within the operated proximal femur - mean pixel intensity within the control proximal femur) / mean pixel intensity within the control proximal femur].

Scintigraphy. Regions-of-interest within the proximal femur (Fig. 1G-L) were selected at each time point; the investigator was blinded to the clinical and surgical information, date of examination and results of other imaging studies. A single operator measured the mean intensity of pixels within the ROIs of each hip. The mean pixel intensity results were then matched with the corresponding surgical and temporal information and the following formula was applied: pixel intensity ratio $=[($ mean pixel intensity within the operated proximal femur - mean pixel intensity within the control proximal femur) / mean pixel intensity within the control proximal femur].
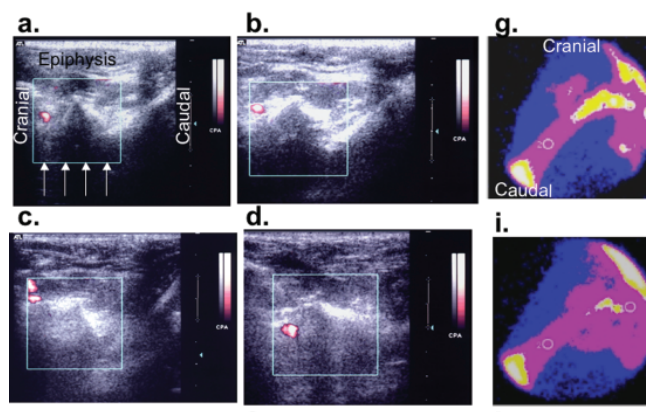

h.
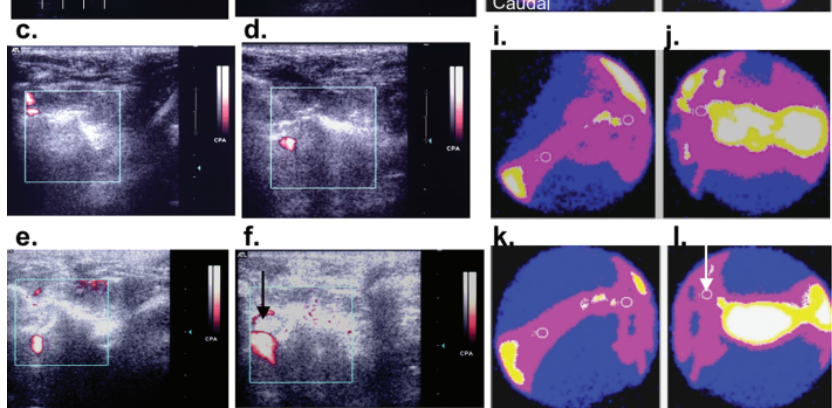

Figure 1 - Corresponding coronal power Doppler sonograms (A-F) and anterior-posterior pinhole scintigraphic (G-L) images of the proximal femura of the same adult rabbit of Fig. 2 and 3 which underwent a left intertrochanteric femoral osteotomy with internal fixation. Please note an increase number of color pixels within the operated proximal femoral epiphysis seen both with Doppler (F) and scintigraphy (L) in the late postoperative images ( 6 weeks after the surgical procedure). These images show that scintigraphy clearly illustrates the hypervascular process as a consequence of healing in the proximal metadiaphysis of the operated femur starting in the early post-operative stage, at a certain point in a more conclusive way than power Doppler sonography. Nevertheless with regard to the diagnostic accuracy for discrimination of the operative status of the proximal femoral epiphysis our study results demonstrated a greater diagnostic performance for Doppler sonography. Number of color pixels calculated in the region of interest within the operated/unoperated hips in the pre-operative, early and late stages for power Doppler sonography were $1867 / 1688,2812 / 3476,12557 / 7560$, and for scintigraphy were 61.6/62.2, 44.8/39.4, 63/51.1. The regions-of-interest used for analysis of power Doppler sonography were the squared color boxes (arrows, A) and for analysis of scintigraphy were the circles at the level of the proximal femoral epiphyses (arrow, H).

\section{Histology}

Preparation of specimens. Following euthanasia of the animals with an overdose of pentobarbital, the disarticulated hips were dissected and the proximal femora were fixed with a $10 \%$ formaldehyde solution for 24 hours. The proximal femora were then decalcified with a $10 \%$ nitric acid solution, dehydrated, and embedded in paraffin. Five $\mathrm{mm}$ thick histologic sections were obtained in a plane perpendicular to the physeal growth plate and were stained with Masson's trichrome ${ }^{16}$ (1) (Fig. 2A-E).

Histomorphometry. The histologic specimens were evaluated by a pathologist blinded to all clinical and surgical information. Standard methods of point counting under light microscopy were used to quantify vascular fractional area and number of vessels per area unit ${ }^{17,18}$. Vascular fractional area and the number of vessels per area unit (in $\mathrm{mm}^{2}$ ) were determined for each specimen by examination of slides under low-power light microscopy. The vascular fractional area was defined as the ratio between number of points of intersection into blood vessels and 


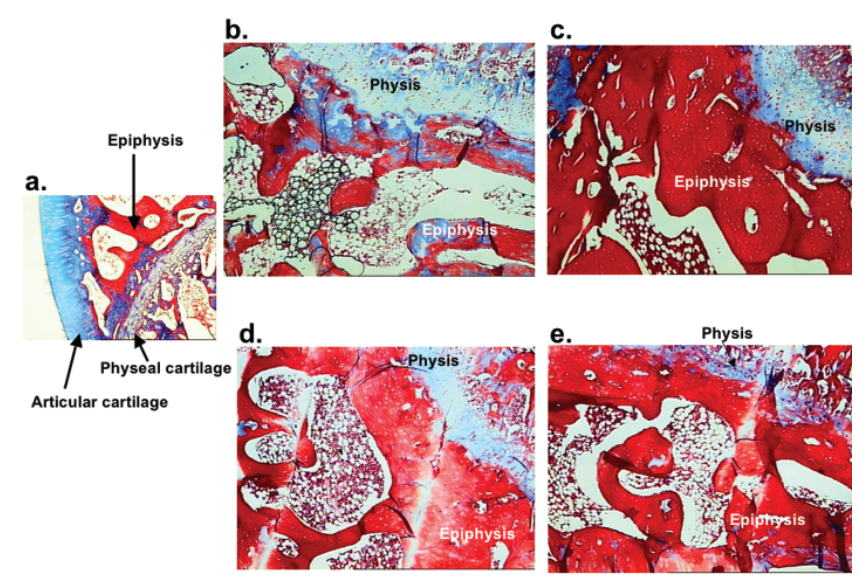

Figure 2 - Photomicrographs of $5 \mathrm{~mm}$ decalcified sections of the operated (left hip, B, C) and non-operated (right hip, D, E) proximal femoral epiphyses-physes of an adult rabbit (same as shown in Figures 1 and 3) obtained 6 weeks following a left intertrochanteric femoral osteotomy and internal fixation, stained with Masson's trichrome method (magnification, 40x (B, D) and 100x (C, E). Caption A illustrates the anatomic location of the histologic sections with the physeal cartilage as the anatomic boundary. Please note the extensive area of bone marrow vessels in the operated proximal epiphysis (arrows, C) as compared with the corresponding region on the contrateral hip (arrows, E).

number of points of intersection into bone tissue. Number of vessels per area unit represented the quantity of vascular points per $\mathrm{mm}^{2}$. The standardized area of analysis included both trabeculae and osteoid within the proximal femoral epiphysis, keeping the physeal cartilage as the anatomic boundary (Fig. 2A-E). The fraction of area and number of vessels per area of the proximal femoral epiphysis were determined in 15 random microscopic fields per histologic section, and were randomly scanned at a magnification of 100x, employing a test eyepiece reticule with 5 parallel lines and 25 points (square lattice test system, $0.902 \mathrm{~mm}^{2}$ ).

\section{Statistical Analysis}

All values were reported as means and standard deviations with individual joints being the experimental units.

Differences in the vascularity of proximal femoral epiphyses that underwent the surgical procedure in comparison with contralateral non-operated epiphyses, assessed by power Doppler sonography or scintigraphy, were evaluated with Wilcoxon rank-sum tests respectively at the pre-operative, 1 week and 6 weeks after the surgical procedure.

Wilcoxon rank-sum tests were also used to evaluate differences in the fractional vascular area and number of vessels per area unit measured in the postmortem proximal femoral epiphyses in operated and non-operated epiphyses.

With regards to histomorphometric methods, receiver operating characteristic (ROC) curves were used to evalu- ate the ability of vascular fractional area and number of vessels per area unit to discriminate hips that were or were not operated upon by means of the Mann-Whitney U statistic, as well as two-tailed and one-tailed t-tests ${ }^{19}$.

Concerning imaging methods, ROC curves evaluated the ability of power Doppler sonography and scintigraphy to discriminate hips that had or did not have an operation (threshold: operated vs non-operated hip), and differentiate hypervascular from non-hypervascular proximal femoral epiphyses. Two thresholds, vascular fractional area and number of vessels per area unit (angiogenic potential), were used for the latter differentiation. For assessment of vascular fractional area, cases with a percentage of vessels $>11$ were considered as positive cases, while those with a percentage of vessels $\mathrm{d} \leq 11$ were considered negative cases. For assessment of angiogenic potential, cases with $>7.8$ vessels per $\mathrm{mm}^{2}$ were considered as positive cases and those with $\mathrm{d} \leq 7.8$ vessels per $\mathrm{mm}^{2}$ as negative cases. Cutoffs were arbitrarily chosen based on expert opinion. Values $\leq$ 0.50 were indicated as non-diagnostic, $>0.50$ and $\leq 0.70$ poor, and $>0.70$ acceptable diagnostic performance ${ }^{20,21}$.

We used AccuROC statistical software version 2.5 (Accumetric Corporation, Montreal, Canada) for the diagnostic test analysis and the SAS ${ }^{\circledR}$ system software package, version 8.2 (SAS Institute Inc.,Cary, NC) for the remaining analyses. Results were considered significantly different if the 2 -tailed $\mathrm{p}$ values were $<0.05$.

\section{RESULTS}

\section{Arteriographic data}

Visually, all radiographic examinations showed increased vascularity (at different degrees of intensity) in the region of the operated proximal femur as compared with the non-operated contralateral side (Fig. 3).

\section{Complications}

All the animals recovered from the operation, and no post-operative infection was clinically identified. In two animals the fixation of the metallic plaques was lost and the plaques were released from their original position.

\section{Imaging methods}

In the pre-operative Doppler and scintigraphy examinations, no differences were noted in the intensity of color pixels representing hip vascularity between the two joints ( $\mathrm{p}=0.54$ for Doppler sonography and $\mathrm{p}=0.92$ for scintigraphy) (Table). 


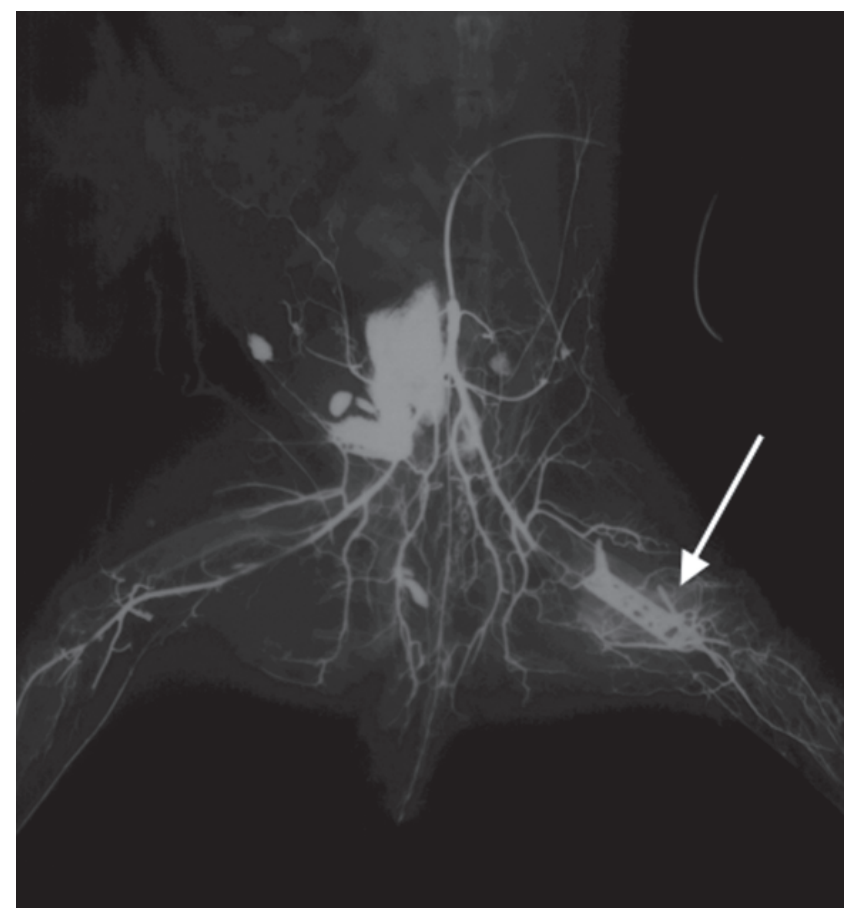

Figure 3 - Arteriographic images of the vascular system of lower abdomen and lower extremities obtained during forced hyperabduction illustrates the location of the osteotomy as well as the longitudinal orientation of the metallic plate and screws in the proximal femoral diaphysis of an adult rabbit 6 weeks after an intertrochanteric osteotomy which was used for stabilization. Intense vascularity is noted at the healing site (arrow) with contrast opacification of both common iliac arteries, both superficial and profunda femoral arteries, and their branches.

In the recent post-operative power Doppler examinations, a tendency towards operated proximal femoral epiphyses presenting with a significantly higher mean number of pixels than non-operated epiphyses $(p=0.089)$ was noted.
However, this difference became statistically significant in the late post-operative power Doppler examinations $(p=0.049)$. Conversely, with scintigraphy the mean number of pixels in the proximal femoral epiphyses did not change significantly according to the operative status (non-operated vs operated) in either the recent $(\mathrm{p}=0.47)$ or late $(\mathrm{p}=0.30)$ post-operative timepoints (Table).

\section{Histomorphometry}

Whereas the vascular fractional area differed between operated and non-operated hips $(\mathrm{p}=0.01)$ in the late postoperative stage (6 weeks after the surgical procedure), the mean number of vessels $/ \mathrm{mm}^{2}$ did not differ significantly $(\mathrm{p}=0.26)$ (Table).

\section{Discriminative power of histomorphometric methods}

The area under the curve (AUC) of the vascular fractional area (AUC $=0.846 \pm 0.099$ ) tended to be greater ( $p=0.005,2$-tailed; $p=0.002$, 1-tailed) than the AUC of the number of vessels $/ \mathrm{mm}^{2}(\mathrm{AUC}=0.358 \pm 0.141)$, suggesting a greater diagnostic accuracy of vascular fractional area to discriminate the operative status of the hips (Fig. 4A).

\section{Discriminative power of imaging methods}

Without reaching statistical significance at a two-tailed test ( $\mathrm{p}=0.11$, 2-tailed; $\mathrm{p}=0.05,1$-tailed), the AUC of the ROC curve of power Doppler (AUC $=0.938 \pm 0.058$ ) was numerically greater than the AUC of scintigraphy $(\mathrm{AUC}=0.688 \pm$

Table - Mean (standard deviation) number of pixels measured in the proximal femora are reported pre-operatively, and at 1 (recent post-operative) and 6 (late post-operative) weeks after a unilateral intertrochanteric femoral osteotomy in rabbits that underwent power Doppler and scintigraphic examinations. Mean (standard deviation) vascular fractional area and number of vessels / area unit measured in the proximal femoral epiphyses with histomorphometric methods in the late post-operative (after 6 weeks) stage are also shown.

\begin{tabular}{|c|c|c|c|c|c|c|}
\hline Imaging method & $\begin{array}{l}\text { Power Doppler scan } \\
\text { Pre-operative stage }\end{array}$ & P-value & Recent post-operative stage & $\mathrm{P}$-value & Late post-operative stage & P-value \\
\hline Operated hips & $3,572(2,409)$ & \multirow[t]{2}{*}{0.54} & $6,006.2(5,198)$ & \multirow[t]{2}{*}{0.089} & $9,128(4,717)$ & \multirow[t]{2}{*}{0.049} \\
\hline Non-operated hips & $2,989.6(1,876)$ & & $3,030.4(2,173)$ & & $5,509.9(4,291)$ & \\
\hline Imaging method & Scintigraphy & \multirow{3}{*}{0.92} & & \multirow{3}{*}{0.47} & & \multirow{3}{*}{0.30} \\
\hline Operated hips & $79.92(34.22)$ & & $69.92(21.66)$ & & $60.44(20.37)$ & \\
\hline Non-operated hips & $81.51(33.76)$ & & $63.78(15.03)$ & & $52.85(9.51)$ & \\
\hline Histomorphometric method & & & & & $\begin{array}{l}\text { Late post-operative } \\
\text { Vascular fractional area }\end{array}$ & P-value \\
\hline Operated hips & & & & & $11.69(1.78)$ & \multirow[t]{2}{*}{0.01} \\
\hline Non-operated hips & & & & & $9.19(2.02)$ & \\
\hline Histomorphometric method & \multirow{3}{*}{\multicolumn{4}{|c|}{ Number of vessels / area unit }} & & \multirow{3}{*}{0.26} \\
\hline Operated hips & & & & & $7.47(1.05)$ & \\
\hline Non-operated hips & & & & & $8.06(1.12)$ & \\
\hline
\end{tabular}




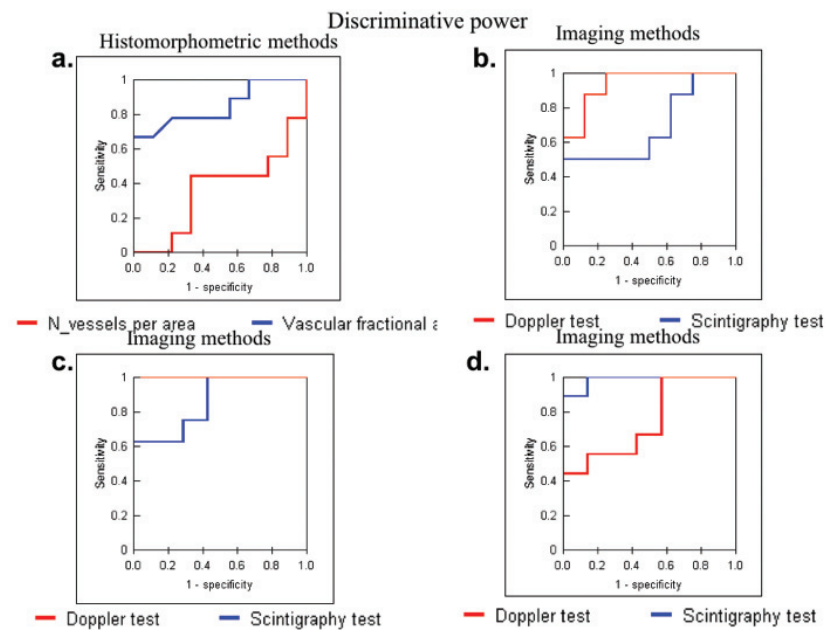

Figure 4 - Areas under the curve (AUC) of measurements for individual methods of imaging or histomorphometry to discriminate the operative status of the hips are shown. Caption A shows a larger AUC for fractional vascular area $(\mathrm{AUC}=0.846 \pm 0.099)$ compared with number of vessels $/ \mathrm{mm}^{2}$ $(\mathrm{AUC}=0.358 \pm 0.141)$, however caption $\mathrm{B}$ reveals no significant differences in AUCs between number of pixels of power Doppler $(\mathrm{AUC}=0.938 \pm 0.058)$ and scintigraphy $(\mathrm{AUC}=0.688 \pm 0.146)$. For discrimination between epiphyses presenting with large ( $\%$ of vessels $>11$ ) or small vascular spaces ( $\%$ of vessels $\leq 11)$ power Doppler performed slightly better $(\mathrm{AUC}=0.99)$ than scintigraphy $(\mathrm{AUC}=0.857 \pm 0.099)(\mathrm{C})$. On the other hand, for discrimination between highly (number of vessels $/ \mathrm{mm}^{2}>7.8$ ) and poorly (number of vessels $/ \mathrm{mm}^{2} \leq$ 7.8) vascularized epiphyses scintigraphy (AUC $=0.984 \pm 0.022)$ performed better than power Doppler sonography (AUC $=0.746 \pm 0.131)(\mathrm{D})$.

0.146) in the late post-operative stage, (Fig. 4B) indicating the potential for power Doppler to present a higher accuracy for discrimination between operated and non-operated proximal femura in a study with a larger sample size. Similar results (without reaching statistical significance at a twotailed test $(\mathrm{p}=0.15,2$-tailed; $\mathrm{p}=0.07,1$-tailed) were noted for power Doppler performing better $(\mathrm{AUC}=0.99 ; \mathrm{p}=0.001$, 2-tailed; $\mathrm{p}=0.006,1$-tailed) than scintigraphy (AUC $=0.857$ $\pm 0.099 ; \mathrm{p}=0.02$, 2-tailed; $\mathrm{p}=0.01$, 1-tailed) in differentiating epiphyses that encompassed large vascular spaces from epiphyses that presented with small vascular spaces as determined by cutoffs of fractional vascular areas in the late post-operative stage (Fig. 4C).

In contrast, when cutoffs of number of vessels / $\mathrm{mm}^{2}$ were taken into consideration, scintigraphy tended to be more accurate $(\mathrm{AUC}=0.984 \pm 0.022 ; \mathrm{p}=0.001,2$-tailed; $\mathrm{p}=0.0006,1$-tailed $)$ than power Doppler $(\mathrm{AUC}=0.746 \pm$ $0.131 ; p=0.1$, 2-tailed; $p=0.05$, 1-tailed) for differentiation between highly vascularized epiphyses (high number of vessels $/ \mathrm{mm}^{2}$ ) and poorly vascularized epiphyses (high number of vessels $/ \mathrm{mm}^{2}$ ) in the late post-operative stage ( $\mathrm{p}=0.07,2$-tailed; $\mathrm{p}=0.04$, 1-tailed) (Fig. 4D).

\section{DISCUSSION}

In this study, over the course of six weeks following unilateral intertrochanteric osteotomies in a rabbit model, we could observe interval vascular and metabolic changes in the proximal femora adjacent to the site of osteotomies; this could be related to revitalization, recollagenization and/ or remodeling. Previous microangiographic studies showed that osteotomies and fractures stimulate the growth of long bones by increasing the local vascularity within the operated proximal femur ${ }^{5}$. In these cases the increased vascular supply derives mainly from periosteal vessels, whereas central vessels in the bone marrow are typically less developed in the operated hip than in the control $\operatorname{side}^{22}$. In some cases vessels penetrate the epiphyseal plate arising from the metaphysis.

Whereas scintigraphy enables visualization of the entire femoral shaft, power Doppler sonography provides information on a limited ROI. Nevertheless, results of our study suggested that the late effect of surgical injury on the vascularity of the proximal femur could be best depicted by power Doppler sonography. Results of Alberty's study ${ }^{23}$ confirm this observation, demonstrating marked enlargement of the epiphyseal arteries in rabbits' distal femora as a result of physeal distraction, with vascular anastomoses being noted across the physes six weeks after the injury insult. Previous studies ${ }^{12}$ that assessed the revascularization of the femoral head in Legg-Calve-Perthes' disease showed that contrast-enhanced power Doppler signals correlated well with clinical findings but were unable to differentiate distinct scintigraphic phases of the disease. In this study, power Doppler showed large AUCs representing improved accuracy of the method to differentiate vascular fractional areas within histologic specimens of proximal femoral epiphyses. Given the existence of large vascular spaces in operated hips, power Doppler sonography could potentially be a useful imaging tool for determining the degree of vascularity within the bone marrow of these hips. Whereas visualization of the proximal femoral vascularity with power Doppler sonography is inconsistent and may not provide the detailed information about perfusion that is required to diagnose focal areas of ischemia ${ }^{13}$, it may provide accurate information on increased vascularity if performed by experienced hands. Further long-term prospective investigation is needed to determine whether this information can predict the future longitudinal bone growth on the side of the bone injury.

Despite the lower spatial resolution of scintigraphy compared with sonography ${ }^{24}$, scintigraphy tended to best discriminate the number of individual vascular points per area in histologic specimens compared with power Doppler sonography. This is most likely related to the capability of scintigraphy to capture metabolic changes within anatomic structures. 
The major limitation of this study was its small sample size. Further research is required to determine the effect of intertrochanteric bone injury on the adjacent epiphysis in larger samples. Another limitation of this technique for use in humans, most notably in children, was that joint motion (which was not noted in this study because the animals were anesthesized during the scans) often requires use of color Doppler rather than power Doppler; also, changes in filter and gain to minimize motion artifacts should be used. Moreover, the greater ossification of the proximal femur in older children and adults may limit the utility of color Doppler. Finally, changes in vascularity of the proximal femoral epiphyses were attributed to the prior surgical procedures in this study, however no correlative histologic analysis of the surgical beds were performed and a great variability in the quantity of epiphyseal color pixels was noted between rabbits' joints. This could be explained by inherent factors, surgical outcomes such as unexpected post-operative changes in position of fixation plates in some cases, and the degree of stress of the femoral heads. More remodeling was expected to occur in greater stressed areas of the femoral head ${ }^{8}$.
In summary, each imaging modality, power Doppler or scintigraphy, has a specific value for post-operative imaging of intertrochanteric osteotomies in identifying late histologic vascular events in the proximal femur of a bone injury rabbit model. Power Doppler sonography is very accurate for discriminating vascular fractional areas, while scintigraphy is best for discrimination of the number of vascular points per area unit. Further longitudinal research in humans is warranted on the basis of these preliminary results.

\section{ACKNOWLEDGEMENTS}

We acknowledge Mirian Roseli Okamoto for consultant advice on scintigraphy, Miguel da Silva Pacos Junior, Rita de Cassia Oliveira Silva, and Jose Eustaquio da Costa for helping with the preparation of histologic specimens, Niels V. R. Celeghin for the data analysis, and Nei Botter Montenegro, Francisco Laurindo, Claudio Campi de Castro, and Giovanni G. Cerri for mentoring and infra-structural support for the research study.

\section{RESUMO}

Doria AS, Cunha FG, Modena M, Rodrigues CJ, Garcez AT, Junior RG, Bolliger Neto R, Melo IB, Buchpiguel C, Molnar LJ, Guarniero R Efeito da Osteotomia Intertrocantérica no Femur Proximal de Coelhos: Avaliação com Ultra-sonografia Power Doppler e Cintilografia. Clinics. 2007;62(6):741-8.

OBJETIVO: Regeneração em casos de lesão óssea resulta em aumento da vascularização local e remodelamento da medula óssea adjacente. A caracterização imagenológica de padrões vasculares e metabólicos no fêmur proximal após uma osteotomia intertrocantérica pode auxiliar ortopedistas a decidirem qual a terapêutica mais apropriada. O objetivo deste estudo foi avaliar as alterações temporais observadas por ultra-sonografia Doppler e cintilografia no fêmur proximal após a realização de uma osteotomia intertrocantérica; e comparar achados imagenológicos e histomorfométricos no estágio pós-operatório tardio (6 semanas após a cirurgia) num modelo animal de lesão óssea.

MATERIAIS AND MÉTODOS: Ambos os quadris de 12 coelhos adultos foram examinados por ultra-sonografia power Doppler e cintilografia antes e após (7 dias e 6 semanas) uma osteotomia unilateral. A acurácia dos métodos de imagem foi avaliada usando-se o status operatório dos quadris and os resultados histomorfométricos (área vascular fracional e número de vasos/unidade de área) como medidas de referência.

RESULTADOS: Uma diferença significativa foi observada entre o número médio de pixels presentes no fêmur proximal operado e não-operado ao exame de power Doppler obtido no estágio pós-operatório tardio $(\mathrm{P}=0.049)$. Embora ser atingir significância estatística, a área abaixo da curva ("area-under-the-curve") dos exames de power Doppler $(\mathrm{AUC}=0.99)$ for numericamente superior à área abaixo da curva dos exames de cintilografia (AUC= $0.857 \pm 0.099)(\mathrm{P}=0.15)$ para diferenciar fêmures proximais com relação a suas áreas vasculares fracionais no estágio pós-operatório tardio. Ao contrário, a cintilografia tendeu a apresentar uma "performance" diagnóstica superior $(\mathrm{AUC}=0.984 \pm 0.022)$ em relação ao Doppler (AUC $=0.746 \pm 0.131$ ) para demonstrar a quantidade de vasos por unidade de área $(\mathrm{P}=0.07)$ no estágio tardio.

CONCLUSÃO: Nossos resultados despertam a importân- 
cia de continuar-se investigando o valor de diferentes métodos de imagem para se avaliar achados patológicos após a realização de cirurgias do quadril. A ultra-sonografia power Doppler demonstrou maiores áreas abaixo da curva (representando maior acurácia) para discriminar áreas vasculares fracionais e cintilografia, para discriminar quantidade de vasos/unidade de área.

UNITERMOS: Osteotomia Intertrocantérica. UltraSonografia Power Doppler. Cintilografia. Coelhos. Fêmur.

\section{REFERENCES}

1. Fujiki EN, Kuwajima SS, Honda EK, Milani C, Porto LC, Chikude T, et al. - Sugioka's Modified Hungria-Kramer intertrochanteric osteotomy in the treatment of severe slipped capital femoral epiphysis. J Pediatr Orthop 2005;25:450-5.

2. Aksoy MC, Cankus MC, AlanaY A, Yazici M, Caglar O, Alpaslan AM. Radiological outcome of proximal femoral varus osteotomy for the treatment of lateral pillar group-C Legg-Calve-Perthes disease. J Pediatr Orthop B 2005;14:88-91.

3. Yang SH, Huang SC. Valgus osteotomy for congenital coxa vara. J Formos Med Assoc 1997;96:36-42.

4. Kay RM, Rethlefsen SA, Hale JM, Skaggs DL, Tolo VT. Comparison of proximal and distal rotational femoral osteotomy in children with cerebral palsy. J Pediatr Orthop 2003;23:150-4.

5. Bohr H, Hansen-Leth C, Reimann I. On the influence of intertrochanteric osteotomies upon the growth and vascularization of the proximal part of the femur in young rabbits. Acta Orthop Scand 1970;41:619-627.

6. Hedstrom O. Growth stimulation of long bones after fracture or similar trauma. A clinical and experimental study. Acta Orthop Scand 1969;Suppl 122:1-134.

7. Sunden G. Some aspects of longitudinal bone growth. An experimental study of the rabbit tibia. Acta Orthop Scand 1967;Suppl 103:7.

8. Lane LB, Villacin A, Bullough PG. The vascularity and remodelling of subchondrial bone and calcified cartilage in adult human femoral and humeral heads. An age- and stress-related phenomenon. J Bone Joint Surg Br 1977;59:272-8.

9. Doria AS, Guarniero R, Molnar LJ, Modena M, Cunha FG, DE Godoy JR, et al. Three-dimensional (3D) contrast-enhanced power Doppler imaging in Legg-Calve-Perthes disease. Pediatr Radiol 2000;30:8714.

10. Doria AS, Kiss MH, Lotito AP, Molnar LJ, DE Castro CC, Medeiros $\mathrm{CC}$, et al. Juvenile rheumatoid arthritis of the knee: evaluation with contrast-enhanced color Doppler ultrasound. Pediatr Radiol 2001;31:524-31.

11. Doria AS, Guarniero R, Cunha FG, Modena M, de Godoy RM JR, Luzo C, et al. Contrast-enhanced power Doppler sonography: assessment of revascularization flow in Legg-Calve-Perthes' disease. Ultrasound Med Biol 2002;28:171-82.

12. Doria AS, Guarniero R, Godoy RM JR, Buchpiguel C, Modena M, Cunha FG, et al. Contrast-enhanced power Doppler imaging: comparison with scintigraphic phases of revascularization of the femoral head in Legg-Calve-Perthes disease. J Pediatr Orthop 2002;22:471-8.
13. Barnewolt CE, Jaramillo D, Taylor GA, Dunning PS. Correlation of contrast-enhanced power Doppler sonography and conventional angiography of abduction-induced hip ischemia in piglets. AJR Am J Roentgenol 2003;180:1731-5.

14. Montenegro NB. Comparative evaluation of the influence of iliac osteotomy and femoral subtrochanteric osteotomy on the vascularity of the proximal femoral epiphysis in rabbits. $\mathrm{PhD}$ Thesis, Universidade de Sao Paulo, Brazil, 1998.

15. Wendelin H, Lindgren I. Microangiography of the renal vessels in rabbit Comparison of different methods. Acta Radiol Diagn (Stockh) 1970;10:49-56.

16. Brenner KA, MCConnell MP, Evans GR, Calvert JW. Survival of diced cartilage grafts: an experimental study. Plast Reconstr Surg 2006;117:105-5.

17. Loud AV, Anversa P. Morphometric analysis of biologic processes. Lab Invest 1984;50:250-61.

18. Richards M, Goulet JA, Weiss JA, Waanders NA, Schaffler MB, Goldstein SA. Bone regeneration and fracture healing. Experience with distraction osteogenesis model. Clin Orthop Relat Res 1998;(355 Suppl):S191-S204.

19. Delong ER, Delong DM, Clarke-Pearson DL. Comparing the areas under two or more correlated receiver operating characteristic curves: a nonparametric approach. Biometrics 1988;44:837-45.

20. Hanley JA, Mcneil BJ. The meaning and use of the area under a receiver operating characteristic (ROC) curve. Radiology 1982;143:29-36.

21. Poolman RW, Hanel DP, Mann FA, Ponsen KJ, Marti RK, Roolker L. Trans-Atlantic hospital agreement in reading first day radiographs of clinically suspected scaphoid fractures. Arch Orthop Trauma Surg 2002;122:373-8.

22. Guida G, Cigala F, Riccio V. [On the effects of inter-trochanteric osteotomy on the vascularization of the proximal end of the femur (experimental study)]. Rev Chir Orthop Reparatrice Appar Mot 1969;55:83-8.

23. Alberty A. Effects of physeal distraction on the vascular supply of the growth area: a microangiographical study in rabbits. J Pediatr Orthop 1993;13:373-7.

24. Bushberg JT, Seibert JA, Leidholdt EM, Boone J. The Essential Physics of Medical Imaging. Baltimore, Maryland, Williams \& Wilkins, 1994. 